\title{
Travel Motivation and Intention to Revisit of European Senior Tourists to Thailand
}

\author{
Arisara Seyanont \\ Department of Hotel Management, School of Tourism and Services Industry, University of the Thai Chamber of Commerce, Thailand \\ *Corresponding Author: arisara_sey@utcc.ac.th
}

Copyright $(2017$ by authors, all rights reserved. Authors agree that this article remains permanently open access under the terms of the Creative Commons Attribution License 4.0 International License

\begin{abstract}
The purpose of this study was to investigate travel motivations of European senior tourists to Thailand by adopting the theory of push and pull motivations as a conceptual framework. The objectives of this study were to investigate travel motivation and intention to revisit of European senior tourists to Thailand. Using factor analysis, this study identified six push factors and six pull factors. From the analysis, the relationships between push and pull factors had the highest correlation were "Rest \& Relaxation" and "Shopping \& Travel Distance". The results of regression analysis indicated three push factors: "(1) Novelty/Knowledge Seeking”, “(2) Ego-Enhancement”, and “(5) Socialization” and three pull factors: "(1) Cultural \& Historical Attractions", "(5) Leisure Activities \& Affordable", and "(6) Relaxation Activities" were found to significant impact to the intention to revisit of European senior tourists to Thailand.
\end{abstract}

Keywords European Senior Tourists, Intention to Revisit, Travel Motivation

\section{Introduction}

The senior population has been continuously rising because of longer life expectancy. Recognizing the fact that we are rapidly becoming a "gray society" and several studies explored the theoretical linkage between aging and profession (Uysal 1993). Recently, senior tourism is a fast-growing form of tourism which has attracted the attention of the tourism industry around the world. The characteristics of senior travelers have become an important area of interest because of the market size and its potential for growth (Horneman, Carter, Wei, \& Ruy, 2002). The past studies showed that population age 55 years and above represented one of the fastest growing segments of the world's population (Shoemaker, 1989). Senior people not only have more leisure time, but also have abundant financial assets.
Tourism Authority of Thailand (2015) believes that senior people are the first target group has the potential and purchasing power due to the increasing number of senior people up to $10 \%$ and they can travel without time constraints. In Thailand 2009, all population was $61,937,651$ people and senior people more than 55 years were 9,994,184 people. In travel each time, a senior people spend money average 910 baht per person or including their companion spend money average 1,852 baht. The number of senior people in market tourism was 4,578,000 people, and the revenue from senior tourism was 44,226,000 baht.

The Tourism Authority of Thailand has laid down three measurable rules to assess a tourist segment; these are cluster, size, and growth. First, the global senior tourists are an outstanding cluster that has different needs and wants from other tourist groups. Second, the size of global senior tourists is substantial enough to be a lucrative segment for any national marketing campaign. Third, the global senior tourist segment is growing and actually growing more rapidly than any other tourist groups. According to the Tourism Authority of Thailand (2015), the number of European tourist arrivals to Thailand January - December 2011 by frequency of visit, the first visit of European tourist was $1,849,755$ tourists and revisit to Thailand was 3,083,679 tourists. According to the Ministry of Tourism and Sports, Thailand (2015), the number of inbound European tourists from January to December 2015 was $3,805,011$ tourists, from January to December 2014 was $4,083,835$ tourists, from January to July 2013 was $3,694,477$ tourists, and from January to December 2012 was $5,650,619$ tourists. The outcomes of the Ministry of Tourism and Sports, Thailand (2011), noted that the number of European tourists aged 55-64 was 530,287 tourists, and aged 65 and over was 171, 261 tourists.

Thailand has the capacity to develop as a senior tourist destination due to the good reputation of Thai hospitality, the variety of tourism attractions and available activities, the offer of beach, mountain, rural and urban tourism options, the existing image of Thailand as a health tourism destination, etc. However, Thailand lacks a coordinated 
policy for developing further the senior tourism market. Therefore, this study was to investigate travel motivations of European senior tourists to Thailand by adopting the theory of push and pull motivations as a conceptual framework. Specially, the objectives were (1) to investigate push and pull factors that influence the European senior tourists to visit Thailand, (2) to identify European senior travel motivation determinants by examining the relationship between push and pull motivation, socio-demographic variables, and intention to revisit Thailand, and (3) to identify the overall travel experiences of European senior tourists.

\section{Methodology}

The data used in this research were collected from European senior tourists who were aged 55 years and above, arriving from European countries and stay in Thailand on December 2015. Using a convenience sampling method, data were collected at Suvarnabhumvi International Airport by departure at Silom Road, BTS Saradaeng, Pattaya, and Samui. To ensure a high return and usable rate, questionnaires were collected and checked for completeness. A total 500 usable questionnaires were obtained.

The questionnaire was developed based on comprehensive review literature of push and pull motivation (Jang \& Wu, 2006; Sangpikul, 2008; Batra, 2009). Based on the review of literature, a total of 20 motivational items were generated for each set of push and pull factors were rated on 5-point Likert scale ranging from 1 (strongly disagree) to 5 (strongly agree). The questionnaire was divided into four sections. First, the sample was profiled by socio-demographic characteristics. Second, containing push factors (reasons/desires for traveling), respondents were asked to indicate their agreement with the statements describing their reasons for traveling abroad. Third, containing pull factors (destination-based attributes), respondents were asked to rate the attractiveness of destination attributes that draw them to Thailand. Fourth, intention to revisit Thailand was asked to rate on 5-point Likert scale ranging from 1 (strongly disagree) to 5 (strongly agree).

The data analysis consisted of sixth steps. First, a profile of the sample was obtained from the socio-demographic questions. Second, descriptive statistics were used to compute the mean score on ratings of push and pull motivation items by European senior tourists. Third, principal component factor analysis with varimax rotation was performed to identify underlying dimensions associated with push and pull motivations of European senior tourists. Only items with factor loading greater than 0.4 were retained for each factor grouping. Factors with eigenvalues greater than 1 were reported in the final factor structure. Fourth, bivariate correlation analysis conducted to examine the relationships among the push and pull factors derived from factor analysis. Fifth, multiple regression analysis, using the 0.05 level of significance, was employed to examining push and pull factors will positive impact to the intention to revisit Thailand. Sixth, multiple regression analysis, using the 0.05 level of significance, was employed to examine whether socio-demographic characteristics influence push and pull factors.

\section{Results and Discussion}

\subsection{Sample Profile}

The socio-demographic characteristics of the sampled European senior tourists were profiled and presented in Table 1 . The proportion of male respondents $(54 \%)$ was higher than that of females $(46 \%)$. The majority of respondents were married with children (38.6\%). About $23.2 \%$ had education at the graduated college degree. The socio-demographic profile showed that $45.6 \%$ of European senior tourists aged between 65-74 years old. The respondents had different occupations, $33.2 \%$ were business owner-self-employees, $\quad 13.4 \%$ were professional, technicians, and housewife, $12.6 \%$ were retired, $11.6 \%$ were company employee, and $9.8 \%$ were other occupation. The majority of respondents came from United Kingdom $9.4 \%$, and from Denmark $8.4 \%$. The respondents had income source $40.6 \%$ was own savings and $20.8 \%$ was pension. About $34.4 \%$ the respondents came to Thailand about three times, $20.6 \%$ came to Thailand two times, $16 \%$ came to Thailand four times, $14.6 \%$ came to Thailand one time, and $14.4 \%$ came to Thailand more than four times.

\subsection{Mean Scores Ratings of Push and Pull Motivation Items by European Senior Tourists}

Table 1, ranking the mean of push and pull motivational items, the results indicated that the top five push motivation items which most participated by European senior tourists when visiting Thailand were: 1) "I want to enjoy and make myself happy while traveling.", 2) "I want to experience cultures that are different from mine.", 3) "This is the time I can escape from the ordinary or routine environment at home.", 4) "I can fulfill my dream and self-curiosity about the country I want to visit.", 5) "I can talk about the places visited and the things I have seen in a foreign country.". The finding showed some similarities with previous studies (Sangpikul, 2008; Jang and Wu, 2006; Heung et al., 2001) And the top five pull motivation items which most participated by European senior tourists when visiting Thailand were: 1) "Cultural and historical places/sites", "Thai food", 2) "Thai arts and cultures", 3) "Thai temple.", 4) "availability of travel related information", 5) "seasides/beaches". 
Table 1. Mean Scores Ratings of Push and Pull Motivation Items by European Senior Tourists

\begin{tabular}{|c|c|c|}
\hline Motivational Items & Mean (SD) & Rank \\
\hline Push motivational items & & 1 \\
\hline $\begin{array}{c}\text { I want to enjoy and make myself happy while traveling. } \\
\text { I want to experience cultures that are different from mine. } \\
\text { This is the time I can escape from the ordinary or routine } \\
\text { environment at home. }\end{array}$ & $4.15(0.806)$ & 3 \\
\hline $\begin{array}{c}\text { I can fulfill my dream and self-curiosity about the country I } \\
\text { want to visit. }\end{array}$ & $4.05(0.854)$ & 4 \\
\hline $\begin{array}{c}\text { I can talk about the places visited and the things I have seen in } \\
\text { a foreign country. }\end{array}$ & $4.04(0.873)$ & 5 \\
\hline Pull motivational items & $4.00(0.873)$ & \\
\hline Cultural and historical places/sites & $3.98(0.854)$ & 1 \\
\hline Thai food & & 1 \\
\hline Thai arts and cultures & $4.13(0.75)$ & 2 \\
\hline Thai temples & $4.13(0.838)$ & 3 \\
\hline Availability of travel related information & $4.09(0.807)$ & 4 \\
\hline Seasides/beaches & $4.07(0.773)$ & 5 \\
\hline
\end{tabular}

Table 2. Push Motivation Factors of European Senior Tourists

\begin{tabular}{|c|c|c|c|c|}
\hline Push factors (reliability alpha) & Factor & Eigenvalue & Variance & Mean \\
\hline & Loading & & Explained & \\
\hline Factor 1: Novelty/ Knowledge-Seeking (0.696) & & 4.718 & $23.591 \%$ & 3.899 \\
\hline I want to see something new and exciting. & 0.698 & & & \\
\hline I want to see something different that I don't normally see. & 0.636 & & & \\
\hline I just want to travel, to go somewhere and do something in different environment. & 0.630 & & & \\
\hline I want to enhance my knowledge about a foreign country. & 0.629 & & & \\
\hline I want to travel to a country that I have not visited before. & 0.556 & & & \\
\hline Factor 2: Ego-Enhancement (0.609) & & 1.617 & $8.087 \%$ & 3.941 \\
\hline I can talk about my travel experience with other people after returning home. & 0.752 & & & \\
\hline I can spend more time with my couple or family members while traveling. & 0.662 & & & \\
\hline I can talk about the places visited and the things I have seen in a foreign country. & 0.656 & & & \\
\hline \multicolumn{5}{|l|}{ Factor 3: Fulfilling Prestige $(0.603)$} \\
\hline I want to experience luxury things, nice food, and a comfortable place to stay. & 0.772 & 1.344 & $6.718 \%$ & 3.945 \\
\hline I want to visit a country which most people value and appreciate. & 0.664 & & & \\
\hline I want to go to the places my friends want to go. & 0.533 & & & \\
\hline Factor 4: Rest \& Relaxation (0.652) & 0.758 & 1.149 & $5.747 \%$ & 3.954 \\
\hline This is the time I can escape from the ordinary or routine environment at home. & 0.742 & & & \\
\hline \multicolumn{5}{|l|}{ This is the time I can escape from stress in daily life. } \\
\hline Factor 5: Socialization (0.487) & & 1.060 & $5.300 \%$ & 4.011 \\
\hline I want to learn and meet new people. & 0.799 & & & \\
\hline I can fulfill my dream and self-curiosity about the country I want to visit. & 0.628 & & & \\
\hline I want to enjoy and make myself happy while traveling. & 0.415 & & & \\
\hline Factor 6: Cultural Enrichment (0.502) & & 1.027 & $5.136 \%$ & 3.953 \\
\hline I want to see how other people live and their way of life. & 0.785 & & & \\
\hline I want to experience cultures that are different from mine. & 0.669 & & & \\
\hline I want to see and meet different groups of people. & 0.471 & & & \\
\hline Total variance explained & & & $54.579 \%$ & \\
\hline
\end{tabular}

\subsection{Factor Analysis of Push and Pull Motivation}

In this study, it was important to analyze the dimension/factor of the push and pull items in order to better understand the principal driving forces of the senior tourists than looking at individual motivation items (Jang and $\mathrm{Wu}, 2006)$. Factor analysis was used to group the push and pull motivation items with similar characteristics to determine a set of push and pull factors (Table 2 and 3). Six push were derived from the factor analysis of factors analysis of 19 push motivation items and one item was deleted (Table 2) and were labeled: (1) Novelty/Knowledge-Seeking, (2) Ego-Enhancement, (3) Fulfilling Prestige, (4) Rest \& Relaxation, (5) Socialization, and (6) Cultural Enrichment. These factors explained 54.579 percent of the variance. Out of the six underlying push factors; 'socialization' emerged as the most important factor to motivate the European senior tourists with the mean score of 4.011. The reliability alphas to check internal 
consistency of items within each factor ranged from 0.487 to 0.696 .

A factor analysis with varimax rotation was also used to group pull motivation items into similar characteristics (Table 3). Six pull factors included: (1) Cultural \& Historical Attractions, (2) Travel Arrangements \& Facilities, (3) Shopping \& Travel Distance, (4) Safety \& Cleanliness, (5) Leisure Activities \& Affordable, and (6) Relaxation Activities. These factors explained 53.317 percent of the variance. Out of the six underlying pull factors; 'cultural \& historical attractions', 'relaxation activities', and 'leisure activities \& affordable' emerged as the three most important factors to motivate the European senior tourists with the mean score of 4.062, 4.034, and 4.018, respectively. The reliability alphas to check internal consistency of items within each factor ranged from 0.487 to 0.640 .

\subsection{Bivariate Correlation Analysis among Push and Pull Factors}

In this study, bivariate correlation analysis conducted to examine the relationships among the push and pull factors derived from factor analysis. Pearson's correlation coefficient (r) which indicates the strength and direction of the relationship between two variables (Cavana et al., 2001), were determined to measure the association between push and pull factors. Table 4, showed the Pearson's correlation coefficient (r) between each push and pull factors ranged from $0.112-0.093$, indicating low to high relationship. From the analysis, the first highest correlation between push factor (4) Rest \& Relaxation and pull factor (3) Shopping \& Travel Distance $(r=0.093)$. The second highest correlation between push factor (2) Ego-Enhancement and pull factor (5) Leisure Activities \& Affordable $(r=0.092)$.

Table 3. Pull Motivation Factors of European Senior Tourists

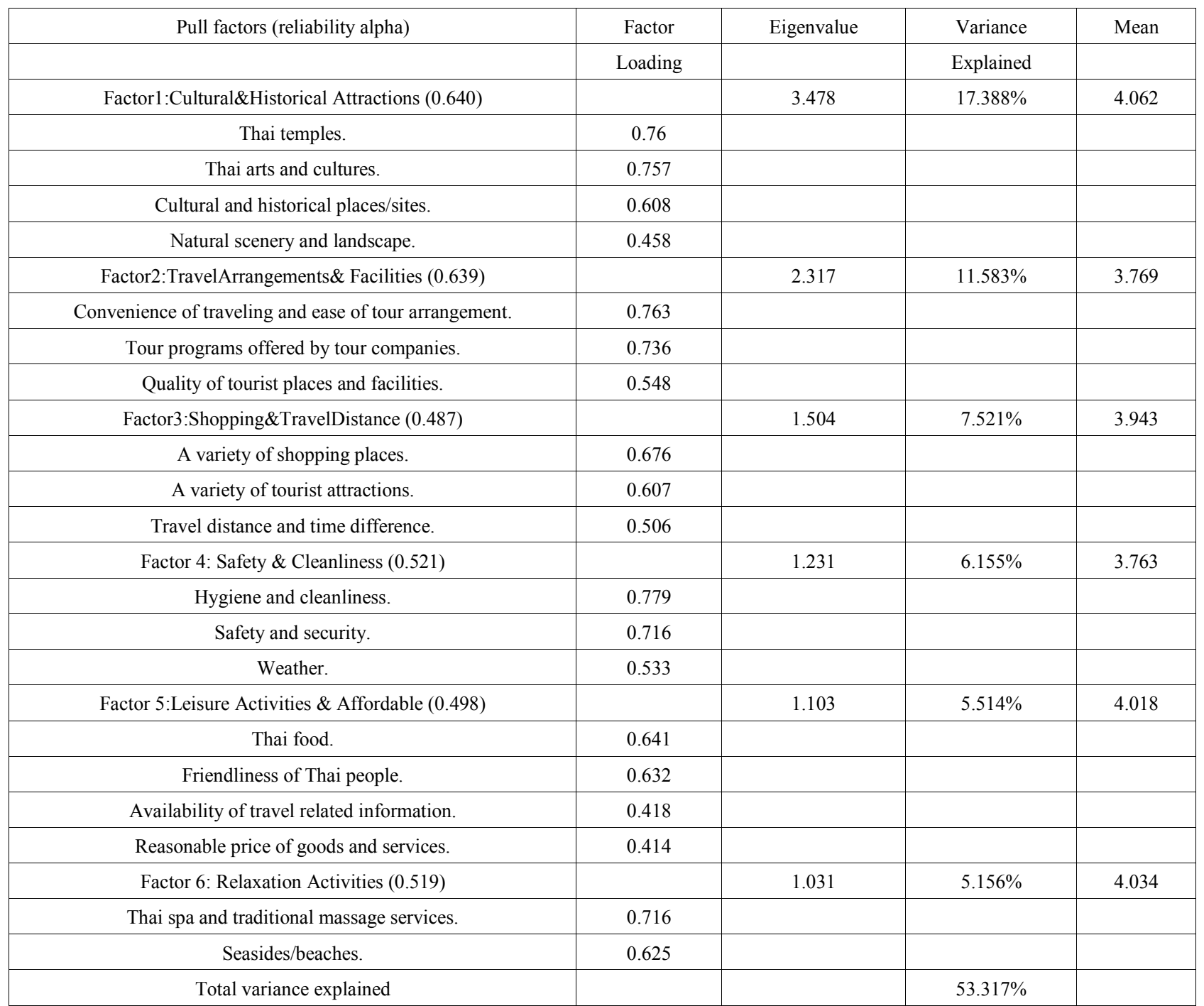


Table 4. Correlation Analysis of Push and Pull Factors

\begin{tabular}{|c|c|c|c|c|c|c|}
\hline & & & Pull factors & & & \\
\hline & (1) Cultural \& & $\begin{array}{c}\text { (2) Travel } \\
\text { Arrangements }\end{array}$ & (3) Shopping \& & (4) Safety \& & $\begin{array}{l}\text { (5) Leisure } \\
\text { Activities }\end{array}$ & $\begin{array}{c}\text { (6) } \\
\text { Relaxation }\end{array}$ \\
\hline & $\begin{array}{l}\text { Historical } \\
\text { Attractions }\end{array}$ & \& Facilities & Travel Distance & Cleanliness & \& Affordable & Activities \\
\hline \multicolumn{7}{|l|}{ Push Factors } \\
\hline (1) Novelty/Knowledge-Seeking & $0.180 * *$ & & & & $0.243 * *$ & $0.293 * *$ \\
\hline (2) Ego-Enhancement & $0.247 * *$ & & $0.149 * *$ & & $0.092 *$ & $0.166 * *$ \\
\hline (3) Fulfilling Prestige & & $0.166^{* *}$ & $0.268 * *$ & & & \\
\hline (4) Rest \& Relaxation & & & $0.093 *$ & $0.134 * *$ & $0.117^{* *}$ & \\
\hline (5) Socialization & & & & & $0.112 *$ & \\
\hline (6) Cultural & $0.117 * *$ & & & & $0.228 * *$ & \\
\hline
\end{tabular}

** Correlation is significant at the 0.01 level (2-tailed)

* Correlation is significant at the 0.05 level (2-tailed)

\subsection{Intention to Revisit Thailand}

In this study was to examine push and pull factors will positive impact to the intention to revisit Thailand. Table 5, showed the results of regression analysis and its coefficients indicated the relationship between independent variables (push factors) and dependent variable (intention to revisit Thailand). It indicated that only three push factors: (1) Novelty/Knowledge Seeking (Beta $\left.=0.239^{*}\right)$, (2) Ego-Enhancement $\left(\right.$ Beta $\left.=0.124^{*}\right)$, and (5) Socialization $\left(\right.$ Beta $\left.=-0.156^{*}\right)$ were found to significantly impact $(\mathrm{p}<$ 0.05 ) on the intention to revisit Thailand.

Table 5. Regression Analysis of Push Factors will Impact on Intention to Revisit Thailand

\begin{tabular}{|c|c|}
\hline & Intention to Revisit \\
\hline Independent Variables & \\
\hline Push Factors & \\
\hline (1) Novelty/Knowledge-Seeking & $0.239^{* *}$ \\
\hline (2) Ego-Enhancement & $0.124^{* *}$ \\
\hline (3) Fulfilling Prestige & -0.021 \\
\hline (4) Rest \& Relaxation & 0.045 \\
\hline (5) Socialization & $-0.156^{* *}$ \\
\hline (6) Cultural Enrichment & 0.048 \\
\hline F-value & $9.281^{* *}$ \\
\hline R Square & 0.102 \\
\hline Adjusted R Square & 0.091 \\
\hline
\end{tabular}

$* \mathrm{P}<0.05, * * \mathrm{P}<0.01$

Table 6, showed the results of regression analysis and its coefficients indicated that the relationship between independent variables (pull factors) and dependent variable (intention to revisit Thailand). It indicated that only three pull factors: (1) Cultural \& Historical Attractions (Beta = 0.196*), (5) Leisure Activities \& Affordable (Beta $=0.194 *$, and (6) Relaxation Activities (Beta $=0.305^{*}$ ) were found to significantly impact $(\mathrm{p}<0.05)$ on the intention to revisit Thailand.

Table 6. Regression Analysis of Pull Factors will Impact on Intention to Revisit Thailand

\begin{tabular}{|c|c|}
\hline & Intention to Revisit \\
\hline Independent Variables & \\
\hline Pull Factor & \\
\hline (1) Cultural \& Historical Attractions & $0.196^{* *}$ \\
\hline (2) Travel Arrangements \& Facilities & -0.058 \\
\hline (3) Shopping \& Travel Distance & -0.028 \\
\hline (4) Safety \& Cleanliness & 0.063 \\
\hline (5) Leisure Activities \& Affordable & $0.194^{* *}$ \\
\hline (6) Relaxation Activities & $0.305^{*}$ \\
\hline F-value & $17.694^{* *}$ \\
\hline R Square & 0.177 \\
\hline Adjusted R Square & 0.167 \\
\hline
\end{tabular}

$* \mathrm{P}<0.05, * * \mathrm{P}<0.01$

\subsection{Seniors' Travel Motivation Determinants}

One of the main objectives of this study was to test whether gender, marital status, educational level, age group, occupation, country of residence, income source, and times to visit Thailand would be able to significantly explain the variances in push and pull factors. Table 7 , the results suggested that gender, marital status, educational level, age group, and occupation were not significant explanatory variables in push factors. Table 8 , the results suggested that only educational level was not significantly affected the pull factors. Based on these results, it can be summarized that there are significant differences in the motives to travel (push factors) and the perception of destination attractions of Thailand (pull factors) among different socio-demographic of the European senior tourists. 
Travel Motivation and Intention to Revisit of European Senior Tourists to Thailand

Table 7. Regression Analysis of Socio-Demographic Characteristics will Impact Push Factors

\begin{tabular}{|c|c|c|c|c|c|c|}
\hline Push Factors & $\begin{array}{c}\text { Novelty/ } \\
\text { Knowledge-Seeking }\end{array}$ & Ego-Enhancement & $\begin{array}{c}\text { Fulfilling } \\
\text { Prestige }\end{array}$ & Rest \& Relaxation & Socialization & $\begin{array}{c}\text { Cultural } \\
\text { Enrichment }\end{array}$ \\
\hline Gender & 1 & 2 & & 4 & 5 & 6 \\
\hline Marital Status & -0.010 & -0.036 & -0.050 & 0.010 & -0.059 & 0.004 \\
\hline $\begin{array}{c}\text { Educational } \\
\text { Level }\end{array}$ & 0.002 & -0.071 & -0.008 & 0.003 & -0.038 & 0.018 \\
\hline Age Group & -0.003 & -0.048 & 0.037 & -0.018 & 0.013 & -0.043 \\
\hline Occupation & 0,016 & 0.082 & -0.037 & -0.018 & -0.053 & -0.038 \\
\hline Residence & $0.147^{* *}$ & 0.029 & -0.005 & -0.016 & 0.062 & -0.040 \\
\hline Income Source & $-0.138^{* *}$ & $0.098^{*}$ & $-0.127 * *$ & 0.029 & $0.114 * *$ & $0.090^{*}$ \\
\hline Times to Visit & $-0.105^{*}$ & $-0.098^{*}$ & 0.086 & 0.021 & 0.075 & 0.029 \\
\hline F-value & $3.670^{* *}$ & 0.016 & -0.038 & -0.090 & 0.071 & 0.090 \\
\hline R Square & 0.057 & $2.197 *$ & 1.801 & 0.630 & $2.377^{*}$ & 1.228 \\
\hline $\begin{array}{c}\text { Adjusted R } \\
\text { Square }\end{array}$ & 0.041 & 0.035 & 0.029 & 0.010 & 0.037 & 0.140 \\
\hline
\end{tabular}

$* \mathrm{p}<0.05, * * \mathrm{p}<0.01$

Table 8. Regression Analysis of Socio-Demographic Characteristics will Impact Pull Factors

\begin{tabular}{|c|c|c|c|c|c|c|}
\hline Pull Factors & Cultural & Travel Arrangements & Shopping & Safety & Leisure Activities & $\begin{array}{l}\text { Relaxation } \\
\text { Activities }\end{array}$ \\
\hline & $\begin{array}{l}\text { \& Historical } \\
\text { Attractions }\end{array}$ & \& Facilities & \& Travel Distance & \& Cleanliness & \& Affordable & \\
\hline & 1 & 2 & 3 & 4 & 5 & 6 \\
\hline \multicolumn{7}{|l|}{ Socio-Demographic } \\
\hline Gender & 0.064 & -0.007 & $-0.138 * *$ & 0.012 & 0.006 & -0.046 \\
\hline Marital Status & -0.007 & -0.039 & -0.040 & 0.038 & -0.014 & $-0.184 * *$ \\
\hline Educational Level & -0.043 & -0.053 & 0.000 & -0.027 & -0.015 & -0.055 \\
\hline Age Group & 0.046 & 0.038 & -0.037 & 0.053 & $-0.110^{*}$ & 0.015 \\
\hline Occupation & 0.049 & -0.074 & 0.025 & $-0.122 * *$ & 0.022 & 0.011 \\
\hline Country of Residence & $0.145^{* *}$ & -0.058 & 0.011 & -0.058 & $0.097 *$ & -0.008 \\
\hline Income Source & -0.026 & 0.053 & 0.035 & -0.031 & $-0.164 * *$ & -0.037 \\
\hline Times to Visit & -0.050 & -0.014 & 0.043 & -0.053 & 0.005 & $-0.114 * *$ \\
\hline F-value & $2.327^{*}$ & 1.169 & 1.521 & 1.852 & $3.395 * *$ & $4.442 * *$ \\
\hline R Square & 0.037 & 0.019 & 0.024 & 0.029 & 0.052 & 0.067 \\
\hline Adjusted R Square & 0.021 & 0.003 & 0.008 & 0.013 & 0.037 & 0.052 \\
\hline
\end{tabular}

$* \mathrm{p}<0.05, * * \mathrm{p}<0.01$

\section{Conclusions}

The purpose of this study was to investigate travel motivations of European senior tourists to Thailand by adopting the theory of push and pull motivations as a conceptual framework. Using factor analysis, this study identified travel motivation factors based on push and pull model. The six push factors were labeled: (1) Novelty/Knowledge-Seeking, (2) Ego-Enhancement, (3) Fulfilling Prestige, (4) Rest \& Relaxation, (5) Socialization, and (6) Cultural Enrichment. The six pull factors were labeled: (1) Cultural \& Historical Attractions, (2) Travel Arrangements \& Facilities, (3) Shopping \& Travel Distance,
(4) Safety \& Cleanliness, (5) Leisure Activities \& Affordable, and (6) Relaxation Activities. Among the identified motivation factors, 'socialization' as a push factor and 'cultural \& historical attractions', 'relaxation activities', and 'leisure activities \& affordable' as a pull factor were viewed as the most important motivations by the European senior tourists.

From the analysis, the relationships between push and pull factors indicated that the value of highest correlation between push and pull factors were 0.093 and 0.092 . The first highest correlation between push factor (4) "Rest \& Relaxation" and pull factor (3) "Shopping \& Travel Distance" $(r=0.093)$. The second highest correlation 
between push factor (2) "Ego-Enhancement" and pull factor (5) "Leisure Activities \& Affordable" $(r=0.092)$. The results suggested that "Rest \& Relaxation" and "Ego-Enhancement" were significantly related to the "Shopping \& Travel Distance" and Leisure Activities \& Affordable" and motived to European senior tourists visit Thailand. It should be noted that this relationship can provide important implications to industry practitioners for developing the product and motivating European senior tourists. In other words, both push and pull factors can help them to understand why people travel and where they go. In addition, push factors helped identify different forces that influenced people to consider taking a vacation, while pull factors can determine the forces that attract them to select a destination (Klenosky, 2002).

Using regression analysis to examine push factors and pull factor will positive impact to the intention to revisit Thailand, the results indicated three push factors:"(1) Novelty/Knowledge Seeking”, "(2) Ego-Enhancement”, and "(5) Socialization" and three pull factors: "(1) Cultural \& Historical Attractions", "(5) Leisure Activities \& Affordable", and "(6) Relaxation Activities" were found to significant predictor of revisit intention to Thailand. Hence, push and pull factors have indeed different effects on revisit intentions in different settings. Prayag (2012) indicated that senior tourists were more likely to revisit if they were motivated by escape and relaxation, while recommendation intentions were predicted by the pull factor of cultural attractions and accommodation.

With regard to the socio-demographic variables, the present study found that education level was not associated with both push and pull factors. This means that, among the socio-demographic variables, only education level cannot significantly explained the variances in European senior tourists' motivations. Based on these results, it can be summarized that there are significant differences in the motives to travel (push factors) and the perception of destination attractions of Thailand (pull factors) among different socio-demographic of the European senior tourists.

\section{Recommendations and Implications}

Regarding the results of push and pull factor analysis, the major motives stimulating European senior tourists visiting Thailand are related to the needs to see and to experience something new, exciting and different from their own culture. In addition, the present study showed some similarities with other studies, e.g. Horneman et al., 2002; Jang and $\mathrm{Wu}, 2006$, Sangpikul, 2008, indicated that the motive of "Knowledge Seeking" was a key push factors for people to travel both domestically and internationally. Furthermore, the findings of this study are also similarities to (Jang and $\mathrm{Wu}, 2006$ and Sangpikul, 2008), discovered that "Historical Sight" appeared to one of the most important pull factors among Taiwanese tourists.
Understanding motivational variations with regard to socio-demographic characteristics should help tourism industries to develop effective marketing programs to attract the senior tourists. By using multiple regression analysis to examine push and pull factors among different socio-demographic characteristics. The results indicated that country of residence, income source, and times to visit Thailand were found to be significant differences in "Novelty/Knowledge-Seeking". And educational level was not associated with both push and pull factors. The results of present study were differences with Sangpikul (2008) identified that gender and education level tended to be more motivated by "Novelty/Knowledge-Seeking" when traveling to Thailand.

Knowing push and pull motivations will also allow travel service providers to be ready to meet or even exceed what tourists want. Jang and $\mathrm{Wu}$ (2006) indicated that "Novelty/Knowledge-Seeking" was the most important push factor and suggested what they have to prepare in order to meet senior tourists' expectation, while "Cleanliness \& Safety" emerged as the most important pull factor. Understanding motivational variations with regard to socio-demographic characteristics should help tourism industries to develop effective marketing programs to attract the senior tourists. The results of present study indicated a number of important differences in the push and pull factors for different socio-demographics of the target. Therefore, the results of the present study can provide useful implications for both policy makers and industry practitioners to effectively design the products or tourism strategies corresponding to the needs and wants of the target.

This study has limitations in association with data used. This study used a convenient sampling method and data were collected on the during Thailand's political situation. Therefore, the result may not truly reflect their actual motivations and perception because political situation may affect the travel motivation factors, attitude, intention to revisit, and their travel experiences. Thailand's political may influence the assessments while they were on the site locations.

\section{REFERENCES}

[1] Batra, A. (2009). Senior Pleasure Tourists: Examination of Their Demography, Travel Experience, and Travel Behavior upon Visiting the Bangkok Metropolis. International Journal of Hospitality \& Tourism Administration, 10, 197-212.

[2] Cavana, R. Delahaye, B., and Sekaran, U. (2001). Applied Business Research: Qualitative and Quantitative Methods. Australia, Milton: John Wiley \& Sons.

[3] Heung, V., Qu, H., Chu, R., (2001). The relationship between vacation factors and socio-demographic and 
traveling characteristics: the case of Japanese leisure travelers. Tourism Management, 22(2), 259-269.

[4] Horneman, L., Carter, R.W., Wei, S., \& Ruys, H. (2002) Profiling the senior traveler: An Australian perspective, Journal of Travel Research, 4(1), 23-37.

[5] Jang, S., \& Wu, C. (2006). Seniors' travel motivation and the influential factors: an examination of Taiwanese seniors. Tourism Management, 27, 306-316.

[6] Klenosky, D.B. (2002). The pull of tourism destinations: A means-end investigation. Journal of Travel Research, 40(2), 385-395.

[7] Ministry of Tourism and Sports, Thailand. (2015) International Tourist Arrivals to Thailand by Nationality at Suvarnabhumi International Airport. Available at http://newdot2.samartmultimedia.com/home/listcontent/11/ 221/276 (accessed 27 December 2015)
[8] Prayag, G. (2012). Senior Travelers' motivations and future behavioral intentions: The case of NICE. Journal of Travel \& Tourism Marketing, 29, 665-681.

[9] Sangpikul, A. (2008). Travel Motivations of Japanese senior travelers to Thailand. International Journal of Tourism Research, 10(1), 81-94.

[10] Sangpikul, A. (2008). A factor-cluster analysis of tourist motivations: A case of U.S. senior travelers. Original Scientific Paper, 56(1), 23-40.

[11] Shoemaker, S. (1989). Segmentation of the senior pleasure travel market. Journal of Travel Research, 27(3), 14-21.

[12] Tourism Authority of Thailand. (2015). Tourism Statistics. Available at http://www2.tat.or.th/stat/web/static_index.php (accessed 27 December 2015).

[13] Uysal, M. Hagan. L. (1993). Motivation of Pleasure Travel and Tourism. Nostrand Reinhold, New York. 